\title{
LADOS E JOGADORES
}

SIDES AND PLAYERS

RESUMO: O problema do artigo é o fundamento das colocações de distinções entre lícito e ilícito. $\mathrm{O}$ argumento do texto é o de que não há algo específico que legitime uma aplicação generalizada dessa distinção. Legitimações são desenvolvidas e construídas em contextos de jogo no qual os agentes usam os recursos que têm a sua disposição para decidir se a diferenciação exigida pelo direito será aplicada ou não em casos que lhes interessam privadamente. Desse modo, escapam de serem detectados como praticantes de algo diferenciado como ilícito por observadores. A análise recorre à teoria dos sistemas sociais de Niklas Luhmann e a discussões teóricas sobre jogo. Palavras-chave: Teoria dos Sistemas. Niklas Luhmann. Play. Atribuição. Jogo.
ABSTRACT: This article deals with the problem of the foundations of the distinction between the lawfulness and the unlawfulness of any act. The point of the text is that no reason genuinely legitimizes a generalized application of such a distinction. Legitimacy is something developed and constructed in players contexts, in which agents use the resources at their disposal to decide whether or not the differentiation required by law applies in cases of their concern. Thus, distinguishing agents manage to avoid being detected as practitioners of something that observers could identify as unlawful. The analysis draws on Niklas Luhmann's theory of social systems and theoretical discussions about play.

Keywords: Systems Theory. Niklas Luhmann. Attribution.

\footnotetext{
${ }^{1}$ Professor titular do Departamento de Filosofia e Ciências Humanas (DFCH) da Universidade Estadual de Santa Cruz (UESC), Ilhéus/BA. Doutor pela Universidade de Hamburgo (Alemanha).
} 


\section{INTRODUÇÃO}

Este artigo trata do contexto em que se legitimam distinções empregadas em sociedade. Distinções entre certo e errado, falso e verdadeiro, válido e inválido, por exemplo, são determinantes para nossas orientações cotidianas e discussões políticas sobre temas relevantes. Mas não há um consenso sobre a existência ou não de uma gênese da validade dessas distinções. Nesse texto, a posição é de que a existência de um lado ou de outro dessas orientações depende de como seus significados são produzidos, aceitos e de como eles fazem sentido. A formalização dessa dependência implica uma perspectiva contextual do desenvolvimento desses tipos de distinções. Para tratar desse problema, o exemplo a ser analisado aqui será o da distinção entre o lícito e o ilícito.

Quando se produz na sociedade distinções entre noções de lícito e lícito ou entre ter ou não direito, temos alguma garantia de que o processo de colocação desta distinção está, ele mesmo, do lado do lícito? Podemos dizer que, quando uma pessoa (como um juiz ou um procurador) ou uma instituição (como um tribunal, a polícia, o direito) comunica que tal assunto ou problema é uma questão de direito (penal, humano, etc.), seja evocando o lícito ou ilícito ou tematizando o ter ou não direito, há uma fundamentação jurídica última que legitima essa comunicação? E, no caso, como essa legitimação lida com a possibilidade de que o "lícito" não seja "ilícito"? Em outras palavras, pode-se ter segurança de que a distinção entre lícito e ilícito está no lado do lícito e não no do ilícito? Em teoria jurídica, Luhmann (1995, p. 72) coloca o problema da seguinte forma: “O código lícito/ilícito não pode ser aplicado em si mesmo sem que resulte em um paradoxo que bloquearia as observações seguintes". De modo que teríamos o problema de saber sob qual base de licitude o direito estabelece o que é lícito e o que é ilícito (LUHMANN, 1995, p. 214-217).

O argumento abaixo desenvolvido é o de que há um estado ou contexto decisivo que ocorre antes de a distinção entre lícito e ilícito fazer sentido em situações comunicativas em que se recorra ao direito como instrumento legítimo dessa distinção. 
Para sustentar essa afirmação proponho uma descrição do que pode ocorrer nesse estado ou contexto prévio - esse é o objetivo deste artigo.

Gostaria de acrescentar algumas reflexões iniciais para evidenciar melhor o problema. Imaginemos que toda comunicação em sociedade (que não seja resultado de reação imediata a uma dor) é elaborada com base em algo que já tenha sido comunicado anteriormente e fixado, seja em registros virtuais, digitais, em papéis ou nas memórias das pessoas. Quando se emite uma comunicação sobre determinado assunto, em nosso caso mais especificamente para avaliar algo como lícito ou ilícito, se toma como base para a formulação temas, palavras, ideias que sejam possíveis de ser reconhecidas, que façam sentido para o interlocutor ou grupo de interlocutores. A emissão de julgamentos pode ganhar força na sensação coletiva de que há um elemento superior que fundamenta o poder de se distinguir e aplicar o resultado a questões do dia a dia, um poder que pode ser exercido mediante o direito. Como se consegue transmitir mais claramente uma noção de justiça e compreensão da situação em alguns casos, tem-se a impressão de que outros casos totalmente diferentes podem ser analisados com base em noções e distinções semelhantes àqueles. Seguem abaixo dois exemplos desses contextos.

Um homem vai à casa de sua ex-esposa e Ihe dispara três tiros no coração. Uma possibilidade de argumentação clara entre o lícito e o ilícito em um caso assim, para além das motivações do agente, evoca uma noção de direito, cuja força poderá ou não refletir em outros casos. Mas em alguns desses casos em que se reflete a força distintiva do direito, a clareza dessa distinção (entre o que se pensa como certo ou errado) pode não estar tão nítida assim. Vejamos: um menino de 19 anos dirige um carro a $120 \mathrm{~km} / \mathrm{h}$, sem efeito de qualquer droga, e atropela fatalmente outro menino que anda de bicicleta na avenida $\mathrm{x}$. No mês seguinte, na mesma avenida, outro menino da mesma idade, nas mesmas condições, atropela fatalmente outro garoto. Poder-se-ia pensar que, pela semelhança, o sentido de aplicação da distinção entre o lícito e o ilícito, considerando suas consequências práticas de julgamento e assim de influência sobre a vida da pessoa, deveria ser mais ou menos o mesmo - já que, hipoteticamente, qualquer atenuante imaginário seria o mesmo para os dois casos. Ou que pelo menos não se viesse a julgar um culpado e outro inocente. No entanto, por exemplo, dadas as condições que um pode ter e 
outro não para contratar determinado advogado e as pré-condições que um pode ter e outro não de ter tido contato com pessoas que poderão influenciar a rota das atividades policiais e judiciárias até um julgamento final, o sentido final do lícito e do ilícito poderá ser transformado conforme o contexto.

Outro exemplo simples em que a evocação da distinção entre lícito e ilícito é fundamentada de modo particular: a corrupção política, praticada por um deputado qualquer envolvido em um esquema de propinas. A detecção do assim considerado "ilícito" e as consequências práticas de tais atos (observados como) corruptos que permitem a propina ocorrer não são tão claros como em nosso primeiro exemplo, e, assim, enquanto não houver detecção ou revelação, não colocam o caso em evidência como um caso do direito. A clareza distintiva (entre lícito e ilícito) de outros casos como o do primeiro exemplo faz com que se reflita e vislumbre a possibilidade de fixação dessa distinção, como se o direito carregasse em si a legitimação pela unidade desse distinguir. Quero dizer, os casos são diferentes, os contextos são diferentes, mas se evoca o mesmo tipo de distinção para que eles sejam analisados (a distinção entre se o que ocorreu é lícito ou ilícito, certo ou errado, conforme ou não o direito), sem que se esclareça os fundamentos da generalização da aplicação dessa perspectiva. Sim, não há tempo para este tipo de esclarecimento nas operações cotidianas, tanto de nossas próprias avaliações como das de qualquer agente ou instituição jurídica. Evoca-se a distinção como se ela fosse passível de ser aplicada em todos os casos em termos de justiça, como se algo fundamentasse essa aplicação generalizada. Esse "algo" existe? Qual é o contexto em que esse tipo de legitimação se desenvolve? Observe-se que não estou me referindo aos motivos e infinitas nuances possíveis de cada caso. Refiro-me à própria distinção que é aplicada em qualquer caso e que é o princípio de qualquer norma derivada desse estado de coisas.

A argumentação aqui é a de não haver algo específico que legitime uma aplicação generalizada da distinção lícito/ilícito. Legitimações são desenvolvidas e construídas em um contexto de jogo no qual os agentes usam os recursos que têm a sua disposição para decidir se a distinção exigida pelo direito será aplicada ou não em casos que lhes interessam privadamente. Por essa via eles podem escapar de ser detectados como 
praticantes de algo distinguido como ilícito por observadores - para explicar este movimento, aprimoro o conceito, já usado anteriormente em outro trabalho (COSTA, 2008), de fuga do campo de detecção de normas e desvios. "Contexto de jogo" (ou quando se falar em "contexto" neste artigo) significará um estado de coisas em que há regras próprias para o comportamento e validade das comunicações e no qual essas regras se tornam flexíveis conforme o sentido que é atribuído por observadores durante este estado. Por isso, as seções a seguir tratarão de atribuição e observação (2) e jogo e campo de detecção (3).

Mesmo que se trabalhe no direito as mais variadas condições para a aplicação prática da distinção entre o lícito e o ilícito (como Jakobs [2008, 2013] tão bem esclarece em seus fundamentos da imputação objetiva, por exemplo), a explicação mais detalhada da contextualização da validação dessa distinção continua, a meu ver, a merecer atenção e novos desenvolvimentos analíticos. Por outro lado, não se pretende aqui simplesmente criticar argumentos populares de sucesso político que demarcam claramente uma distinção entre o lícito e o ilícito, como "bandido bom é bandido morto" ou associações apressadas entre criminalização e pobreza, por exemplo. Há várias teses nas ciências sociais que cumprem muito bem esta função e evidenciam a ingenuidade ameaçadora desses tipos de concepções.

Entre trabalhos importantes para a análise das orientações sociais com base na diferenciação entre o lícito e o ilícito e sua problematização, creio haver por vezes um certo excesso em se evidenciar a existência de mundos diferentes, de dois lados, como se houvesse uma metaperspectiva que pudesse legitimar essa divisão. E aqui, novamente, creio haver espaço para novas aberturas analíticas. Esse modo de diferenciar um lado (positivo) de outro (negativo), distancia-se da perspectiva de "contexto de jogo" e observadores aqui proposta. Ele prende-se ainda, a meu ver, à perspectiva de alguma forma de lado. O lado pode ser o "mundo do crime", como se houvesse dois ou mais mundos, ou o legal e o ilegal, ou o lícito. Seguem ilustrações de alguns estudos relevantes no campo da sociologia brasileira que se apoiam na existência desses "lados", ainda que de modo crítico e por vezes tentando ultrapassar essa dicotomia. É apenas uma forçosa seleção, a qual serve como ilustração inicial e não será aprofundada nomeadamente neste 
artigo. Não é também uma crítica sistemática, pois são trabalhos estimulantes e esclarecedores.

Em meado da década de 70, Ramalho (2002) recolheu histórias de vida em 34 entrevistas com presos para descrever como o "criminoso" vê o "mundo do crime"; mais especificamente, como a consciência do preso, influenciado por sua origem social, percebe a situação de ele ser um "delinquente". Os próprios presos classificam-se entre os que optam pelo "mundo do crime" e os que se recuperam, o que era percebido como "símbolo de riqueza". A concepção de um único mundo (sem a separação de um mundo do crime e outro que não o seja, mas sim evidenciando a dependência entre eles) é entendida por Ramalho como um paradoxo, conforme sua hipótese principal: "Crime e delinquência seriam também parte do próprio sistema social que os condena e, paradoxalmente, deles não pode prescindir" (RAMALHO, 2002, p. 20). Feltran (2008a, p. 15) afirma que "há interações complexas, e em diversos níveis, entre o 'mundo do crime', a sociabilidade urbana e as políticas públicas, e a opção por investigar trajetórias de 'adolescentes infratores' pode ser um modo de acessá-las". Ele empreende essa investigação na forma de uma etnografia para observar dimensões "dos circuitos sociais por onde passam essas trajetórias". Na dimensão das redes de sociabilidade estariam a família, a igreja e o "mundo do crime". O "mundo do crime", em sua concepção nativa, significa "conjunto de códigos e sociabilidades estabelecidas, prioritariamente no âmbito local, em torno dos negócios ilícitos do narcotráfico, dos roubos e furtos" (FELTRAN, 2008b, p. 93). Há um "mundo crime" e um "mundo social legítimo" e os jovens da periferia atuariam entre esses mundos. Telles (2012) afirma que entre o ilegal e o ilegal há "dobras", nas quais se articulam "jogos de poder". Há uma "transitividade" de pessoas e mercadorias entre o "formal e o informal, o legal e o ilegal, o lícito e o ilícito". Essa transitividade flui por "fricções engendradas nas passagens dessas fronteiras porosas" (TELLES, 2012, p. 27). Esse movimento foi objeto de descrição da pesquisa coordenada pela autora. Nessas dobras, os jogos de poder permitem negociar o aceitável. As trocas ilegais que ocorrem nas dobras dependem de agenciamentos políticos, os quais, por sua vez, ocorrem nas dobras. A negociação nas dobras envolve a própria aplicação da lei e assim também uma "disputa dos sentidos de ordem" (TELLES, 2012, p. 40). Essa disputa se instala na função de 
ordenamento social do Estado. Como consequência, com base na preocupação com a articulação dessas disputas, o Estado redefiniria constantemente seus "modos de governar e legislar" (TELLES, 2012, p. 41).

Essas e outras pesquisas semelhantes me levaram a refletir sobre a perspectiva de análise e a oferecer uma perspectiva complementar, pois essas abordagens acima também tentam investigar algo que vai além de simples lados. A ideia de "dobras", por exemplo, se aproxima da perspectiva deste artigo; no entanto, a meu ver, ainda que tente evitar, sustenta-se na composição de lados (os quais de algum modo se encontrariam nas dobras).

A posição deste artigo é que não se deveria considerar primordialmente a existência de mundos diferentes, principalmente com os quais se distingue o que pertence às atividades "criminosas" ou não, mesmo que haja pontos (espaciais/temporais) nos quais eles sejam articulados. Pois é justamente a fusão desses mundos e lados, ou a força da rede para a qual participantes de diferentes categorias econômicas e funções contribuem, que caracterizariam o contexto de jogo no qual as validades do que possa ser lícito ou ilícito são decididas.

Este trabalho também pode ser considerado uma continuação de reflexões já desenvolvidas anteriormente, com base em dados levantados (Costa, 2015 e 2016), para as quais agora, então, empreendo uma tentativa de descrição complementar das situações.

\subsection{Considerações sobre a metodologia}

A base da análise é o método funcionalista da teoria dos sistemas sociais de Niklas Luhmann. Essa perspectiva de análise será aqui empregada de modo avançado. Portanto, ainda que sejam explicados alguns conceitos básicos da teoria e eu tenha me esforçado em listar vários exemplos como ilustração, é desejável que se tenha noções básicas da mesma e que se tenha refletido sobre seu uso prático para acompanhar o aproveitamento que se faz dela.

Explicarei abaixo o a) nível de análise sistêmica que emprego (cuja estrutura de explicação retiro principalmente de Luhmann (1987a, p. 15-18, cap. 9-10) e de Baraldi, 
Corsi e Esposito (1987, p. 176-178), b) a dimensão de sentido da qual parto (cuja base está em Luhmann [1999, p. 1136-1141]) e c) minha orientação para a análise ${ }^{2}$.

a) Na clássica apresentação dos níveis sistêmicos em "Sistemas sociais", Luhmann distingue três níveis a serem considerados para uma abordagem com teorias dos sistemas: um primeiro nível que difere os sistemas do resto. Aqui é importante considerar a diferença primordial sistema/ambiente e a diferenciação dos sistemas sociais de outros sistemas. No segundo nível há distinção entre máquinas, organismos, sistemas sociais e sistemas psíquicos. Aqui é necessário entender a especificidade dos sistemas sociais. Para isso os conceitos de sentido e comunicação são essenciais. O sentido diferencia os sistemas sociais e psíquicos dos sistemas biológicos (organismos) e a comunicação diferencia a operação do sistema social (comunicação) da do psíquico (os pensamentos). Aqui a questão fundamental orientadora é como, partindo do problema inicial da dupla contingência, as comunicações, que não têm durações (ocorrências [Ereignisse]), são constantemente produzidas, mantidas e conectadas umas com as outras. No terceiro nível se distingue três tipos de sistemas sociais: as interações, as organizações e as sociedades. Luhmann esclarece a realidade social mediante a explicação das autonomias e interdependência deles. Por isso falamos de sistemas sociais, no plural. De modo que ainda que os sistemas parciais (jurídico, científico, econômico, político etc.) sejam designados de "sistemas sociais", eles não devem ser analisados da perspectiva somente de um desses tipos, e sim em relação à autonomia e à interdependência deles. Esclareço isso, porque percebo certo mal-entendido em relação ao princípio do que pode e do que não pode ser analisado pela teoria dos sistemas, como por exemplo, que o sistema jurídico não poderia ser analisado do ponto de vista da interação. O próprio Luhmann fornece vários exemplos (com interações no sistema jurídico) que evidenciam o uso dessa interdependência. Além disso, qualquer comunicação (inclusive as que resultam de interações) em sociedade é passível de ser analisada do ponto de vista sistêmico, desde que, claro, o observador assim o faça. A conexão ou interdependência entre esses três tipos (e os sistemas parciais) do terceiro nível é, em termos gerais, a seguinte: a sociedade (que é conjunto de todas as

\footnotetext{
${ }^{2}$ Para um aprofundamento sobre metodologia de análise com teoria dos sistemas de Luhmann, ver Costa (2020).
} 
comunicações sociais que se pode esperar) produz a determinação das condições de certas interações (que surgem sempre no presente entre presentes e incluem tudo aquilo que pode ser tratado como presente) e cria (em sistemas parciais e nas organizações) um ambiente social estruturado ao qual as interações acabam se adequando ${ }^{3}$.

Neste artigo essa interdependência será detalhadamente analisada para explicar as condições de uso de um determinado tipo de distinção: como são geradas e mantidas pelos sistemas parciais e usadas nas interações as condições sob às quais se articulam a distinção lícito/ilícito.

b) A teoria de Luhmann conecta três teorias, comunicação, evolução e diferenciação, para descrever a autopoiese da sociedade. Essas teorias interpretam as dimensões de sentido desta autopoiese. É recomendável saber de qual dimensão de sentido se começa, para assim ter controle sobre a respectiva aplicação conceitual na análise. A relação entre as dimensões de sentido e o princípio de início de uma análise com base na teoria dos sistemas sociais de Luhmann é a seguinte:

Ao se partir da dimensão temporal, se abrem duas vias de explicação: começando pela ideia de processo, se assume a ideia de continuidade. Começando pela ideia de operação e ocorrência (Ereignis), se assume a ideia de descontinuidade. Ao se partir da dimensão material, a ênfase recai na posição referencial em que se vê outros sistemas se diferenciando do ambiente e se colocando (o próprio observador) a partir de um sistema. Ao se partir da dimensão social se evidencia a bifurcação (sim/não) que se abre em qualquer comunicação (para manter a autopoiese) e assim a partir daí analisar as preferências que enfocam a probabilidade crescente de aceitação da comunicação proposta.

Neste artigo a partida de análise é da dimensão social de sentido, pois o estudo é principalmente sobre as condições para se aceitar a proposta comunicativa que usa a diferença lícito/ilícito. É claro que as outras dimensões estão presentes, principalmente a temporal, pois é necessária evidenciar na análise o que mantém a comunicação, o que faz

\footnotetext{
${ }^{3}$ Cf. Luhmann (1987a, p. 535-536 e 560-561) e Baraldi, Corsi e Esposito (1987, p. 84).
} 
com que a descontinuidade intrínseca das ocorrências se transforme em conexões contínuas.

c) Mais especificamente, a orientação para a análise é a aplicação da teoria de que distinções produzem formas, as quais, em determinados contextos, emitem o sentido que se busca nas comunicações. Com base no tema aqui discutido, a distinção entre algo que pode ser lícito em relação a todo o resto de possibilidades que não conota uma demarcação - e que assim é tomado como um lado negativo, ou seja, de negação da distinção demarcada - produz a forma lícito/ilícito. Essa forma, mediante uso intensivo de sua distinção, torna-se fixada em uma armazém semântico, por assim dizer, ficando disponível para ser usada, com um sentido que aumente a probabilidade de o interlocutor aceitar o que se diz, em comunicações jurídicas, policiais, de resolução de conflitos ou ainda sempre que o tema girar em torno do que pode ser considerado lícito ou ilícito ou que se tenha de decidir quem tem direito ou não a alguma coisa, ou ainda se algo está ou não conforme uma respectiva norma, lei, etc. Considera-se, então, que em nossa sociedade essa distinção (essa forma de código lícito/ilícito) permanece decisiva, como uma função que se evidencia como base para resolução de conflitos (observando-se, como esclarece Luhmann [1987a, p. 512], que o direito, que usa esta forma, não serve para evitar conflito, mas para evitar a resolução violenta de conflitos mediante comunicação). Mas o que fundamenta essa distinção? O que faz com que um observador em certas situações distinga desse modo e, em outras, em que o tema é resolução de conflito, não? Questões que orientam o procedimento metodológico e nos levam então a procurar por atribuições e distinções anteriores, que possam auxiliar-nos a fundamentar a distinção em questão entre o lícito e o ilícito.

Espera-se que as reflexões aqui desenvolvidas contribuam para complementar a posição de várias teorias da sociologia e da sociologia jurídica e de resultados de levantamentos empíricos nessas áreas de que a consolidação da percepção de crime, corrupção, desvio e semelhantes é produto de diferentes processos de construções sociais. Discutir os fundamentos da distinção (estatuída e aplicada como válida pelo direito) entre lícito e ilícito concatena-se, a meu ver, diretamente com elementos operacionais relevantes que, espero poder evidenciar aqui, estão presentes naquelas construções. 


\section{ATRIBUIÇÃO E OBSERVAÇÃO}

Para entendermos a proposta de que a distinção entre lícito e ilícito se fundamenta por observações que se orientam por diferentes contextos, propõe-se abordar os conceitos de "atribuição" e "observação". Eles têm sua base na teoria dos sistemas sociais de Niklas Luhmann. Pretende-se assim emitir uma explicação detalhada do que ocorre quando um observador distingue o que vê como sendo algo certo ou errado, lícito ou ilícito, e de como se prepara as condições para este observador ser orientado a perceber o que vê de um determinado modo e não de outro (no caso, a atribuição). Nesta seção também serão necessariamente apresentadas explicações pontuais sobre o direito em Luhmann.

Inicio com uma apresentação geral da teoria centrada no conceito de observação, para entrar a seguir na especificidade desta seção em relação ao argumento do artigo.

$\mathrm{Na}$ perspectiva daquela teoria, as distinções que têm sido exemplificadas neste texto são produções de observadores. A teoria dos sistemas sociais concebe a existência de sistemas sociais como resultado de observações. Sistemas são produtos de observadores que observam, de modo específica e binariamente codificado, outros observadores (sistemas) e tudo aquilo que não se constitui como sistema, ou seja, o ambiente. De modo que a distinção primordial que fundamenta a teoria de Luhmann é a entre sistemas e ambiente ${ }^{4}$.

Observação é a realização operativa de uma distinção (Unterscheidung) mediante designação (Bezeichnung) de um lado (e não do outro) da distinção. Este Não interessa o que observa (que tipo de observador, ou: que tipo de sistema), e sim a operação do observar. A observação introduz a diferença sistema/ambiente na realidade. "Distinção" e "diferenciação" (ou "processo de diferenciação") podem parecer sinônimos, mas frequentemente não têm o mesmo significado na teoria dos sistemas de Luhmann. "Distinção" (Unterscheidung) é empregada para indicar parte da operação da observação que distingue dois lados e os designa, considerando-se que sempre somente um lado é

\footnotetext{
${ }^{4}$ Cf., por exemplo, Luhmann (1987a, p. 242-243).
} 
operacionalizado (na observação de primeira ordem, a qual será explicada abaixo ainda nesta seção) ${ }^{5}$. Nesse sentido é usado também muitas vezes "diferença" (Differenz). A "diferenciação" ou o "processo de diferenciação" (Differenzierung e Ausdifferenzierung) é aplicada no sentido da formação dos sistemas (ao se diferenciarem de seu ambiente), pressupondo-se distinções sistêmicas pré-existentes, sem que a origem daquela formação seja diretamente derivada destas distinções (o que reflete também uma noção de "emergência") 6.

Quando um observador atribui determinada qualidade a alguma coisa, ele a distingue de outra qualquer. Essa afirmação demanda então uma explicação da précondição para a observação: a atribuição. Por que o observador atribui determinada qualidade a algo e não outra coisa? Por que e como, por exemplo, se classifica (se atribui) algo como "ação", conceito tão importante para teorias sociológicas? Luhmann (2008a, p. 251-254) questiona, como se pode atribuir algo à ação sem que se saiba os limites daquilo que se entende como ação. Há limites internos (qual é a motivação do agir?) e limites externos (quais sequências pertencem e quais não pertencem ao agir? Em que ponto da sequência ele inicia e em que ponto ele para?). Essa reflexão sobre os limites serve à construção da resposta à seguinte questão, agora colocada de modo mais preciso: quando o observador quer designar algo como "ação" ele quer distinguir "ação" de quê? (LUHMANN, 2008a, p. 251) O que pertence àquilo que ele designa como ação?

Atribuição é a técnica que orienta a localização das seleções efetuadas. Ou: é a técnica que orienta a localização da ideia de uma origem para algo decorrer de uma maneira e não de outra (LUHMANN, 1981, p. 69). Algo para ser comunicado é selecionado (como veremos melhor mais abaixo). A questão é conferir sentido à seleção feita. Então, voltamos à questão: a que se atribui o que se observa? Tentarei exemplificar: se vejo alguém (A) cantando bem, penso (caso 1) que A está cantando bem e que isso é algo conquistado por ele e que ele faz isso porque, em última instância, ele quer. Ou (caso 2) penso que A canta porque um outro ser não humano ou uma outra coisa qualquer (que posso pensar conhecer ou não, pois talvez seja algo que eu não consiga explicar) faz com

\footnotetext{
${ }^{5}$ Ver, por exemplo: Luhmann (1992, p. 84; 1987a, p. 244).

${ }^{6}$ Cf. Krause (2005, p. 136 e 251).
} 
que A cante assim e lhe tenha talvez concedido essa "aptidão". No caso 1 atribuo o que penso a uma "ação" de A. Nesse modo de pensar, concentro-me no que algo ou alguém (A) está fazendo, no modo como ele está se comunicando e compartilhando (ou participando a alguém) alguma coisa que eu venha a distinguir como informação. Nesse caso, aquele que atribui coloca a si mesmo e a A como sendo livres para, se assim se desejarem, fazer algo diferente, agir diferente (LUHMANN, 1981, p. 74). No caso (2) atribuo o que penso a algo diferente da própria vontade ou capacidade de A. Nesse caso, aquele que atribui e o próprio A estão na situação de "experimentar" / vivenciar" (erleben) algo que não depende deles, que é atribuído a outra coisa. No caso 1 se atribui uma ação a um sistema. No caso 2 se atribui um experimentar ou um vivenciar ao ambiente.

Podemos explicar isso também da seguinte maneira (SAAKE, 2012, p. 77): quando a comunicação é atribuída a um motivo, ela toma a forma de ação, pois ao atribuir a um motivo crio também um agente (que pode ser um sistema social, um sistema psíquico) para este motivo. Com isso se forma algo (fora desse quadro de atribuição a um motivo) que aparece como "sem motivo" e que então é tratado como se fosse um acontecimento do mundo (Weltgeschehen). Nesse caso, então, o "sem motivo" aparece porque a responsabilidade daquilo que está sendo observado não é atribuída à vontade de um ser humano ou de um sistema jurídico, por exemplo. O "sem motivo" é um motivo atribuído ao ambiente naquele momento.

Em diferentes contextos, as atribuições podem ser diferentes. Para a estabilização de expectativas em um sistema social (e assim ele ser possível) tem de surgir regras de atribuição, para, desse modo, ações e vivências serem coordenadas. Quanto mais complexa a sociedade se torna, tanto mais aumenta esse problema. E assim tanto mais ocorre que um sistema social (sistema jurídico, sistema econômico, etc.) atribua a si mesmo seleções. O direito, por exemplo, no decorrer de seu desenvolvimento, é então atribuído ao sistema jurídico, e não mais à lei de um deus (BARALDI; CORSI; ESPOSITO, 1997, p. 24-26).

Em outras palavras, uma das grandes questões da teoria dos sistemas sociais de Luhmann é investigar como é atribuído algo a determinado sistema ou não (como a outro sistema ou a outra coisa qualquer no ambiente). Por que se observa orientado, em última 
análise, por uma codificação binária, seja ela entre poder pagar algo ou não, ter poder não, ser belo ou não, estar imanente ou transcendente, ter capacidade ou não? Ou, no caso principal deste artigo, por que se observa considerando algo como lícito ou ilícito? Podemos agora entender que a operação deste tipo de observação depende de como se atribui sentido ao que é observado.

Mas tem de haver um elemento que desempenhe a coordenação do processo de atribuição. Em "Sistemas Sociais" Luhmann desenvolve uma teoria da comunicação na qual esse elemento é a comunicação, conceito central para o entendimento da estrutura de argumentação sistêmica pretendida (STICHWEH, 2000, p. 212). O "material", por assim dizer, das distinções é retirado de armazéns semânticos e processado por comunicações. Para Luhmann, o processo de cada unidade de comunicação, de cada coisa que de alguma forma é comunicada, resulta da conexão concomitante entre três seleções. Há uma seleção de algo a ser informado (informação), de como esse algo deve ser participado a outro (participação, no original alemão: Mitteilung, no sentido de participar algo a alguém, não no sentido de participar de algo) e de uma compreensão (Verstehen) do outro, observando-se que esta compreensão não depende de um entendimento adequado, basta que o outro compreenda que algo lhe está sendo participado. Ou seja, que ele entenda a distinção entre algo qualquer que está simplesmente sendo dito (sem saber ou perceber que é para ele, pois ele neste caso não distingue que algo lhe está sendo participado) e algo que Ihe está sendo participado. Trata-se da distinção fundamental para que a comunicação ocorra: entre informação e participaçã ${ }^{7}$. Esta compreensão, pelo participante do processo de comunicação em questão (como a consciência de um ser humano), só se manifesta por um outro ato de comunicação que se conecta a essa unidade de comunicação passada. A consciência do participante não se comunica, só a comunicação se comunica (LUHMANN, 1987a, p. 193-198, 310; NASSEHI, 2000, p. 244-245). Importante reter também que não precisa haver um objetivo de comunicação, algo que se queira que

\footnotetext{
${ }^{7}$ Cf., por exemplo, Luhmann (1987a, p. 196-198; 1999, p. 72 e 538; 2008b, p. 111).
} 
seja comunicado. O importante é que o segundo sistema (psíquico ou social) observe uma distinção entre informação e participação ${ }^{8}$.

Exemplo - inspirado em Kneer e Nassehi (2000, p. 82-89) - de como uma comunicação se conecta à outra independente de ser ter entendido exatamente o que o outro queria dizer: um médico diz a um paciente que o resultado de um exame deu positivo. O paciente pensa que é algo bom, porque é "positivo", demonstra esta satisfação e o médico ao perceber essa reação lhe explica que o "positivo" é para a presença de um elemento não desejado em seu corpo. No exato momento posterior em que foi participado ao paciente a informação (para o paciente é informação porque fez uma diferença para ele, a qual inclusive o levou a uma reação) o médico não sabe o que se passa na cabeça do paciente. Ele pode ter entendido ou não o que o médico lhe disse de acordo com aquilo que o médico acha válido como entendimento. Independente disso, as conexões comunicativas seguem, porque há algum tipo de reação que é percebida - seja ela expressa por um gesto ou dita, pois o paciente poderia ter dito que não entendeu e assim se dava seguimento.

A comunicação é realizada por observadores e a observação desses observadores, que vai possibilitar a distinção entre sistema e ambiente, é realizada por observações de segunda ordem. A observação de segunda ordem é a observação de uma observação; é a observação de um observador em relação ao que ele pode ver e ao que ele não pode ver ${ }^{9}$. Não se trata de uma observação de comportamentos, mas de como os indivíduos (se for o caso) observam (LUHMANN, 2008a, p. 155-156). O sistema não pode observar sua própria reprodução no momento em que se reproduz. A distinção inicial é o seu ponto cego (blinder Fleck). No momento exato da distinção aquele que distingue não tem consciência de que distingue. O pensar em distinção não ocorre por aquele que no momento distingue (observação de primeira ordem), ainda que a distinção ocorra. Pode-se fundamentar essa distinção antes ou depois de sua ocorrência. Pode-se antecipar a afirmação de que essa distinção existe ou então discutir sobre ela depois - no caso, seriam observações de

\footnotetext{
${ }^{8}$ Cf. também Stichweh (2000, p. 214).

9 "Observação de segunda ordem" é uma ideia que Luhmann retira de Maturana, 1982, esp. p. 36s, conforme ele informa em Luhmann, 2004, p. 52-53.
} 
segunda ordem. Esse ponto indeterminado de observação (em qualquer distinção de primeira ordem, não somente no direito) é o blinder Fleck (LUHMANN, 2008a, p. 145-146; 1999, p. 426, 882).

No exemplo acima, o médico, no momento em que observa em primeira ordem, simplesmente seleciona um lado (dizer isso ou aquilo, dizer assim ou assado, pensar se o paciente entendeu ou não, etc.) e comunica, sem condições, no momento exato daquelas seleções, de distinguir o que está selecionando (que é também uma distinção). Ele distingue somente um lado. Como observador de segunda ordem, ele pode analisar a reação do paciente e/ou pode refletir sobre a própria decisão que acabou de ter (autorreflexão).

Um outro exemplo, agora direcionado ao tema central deste artigo. Uma observação orientada pela distinção verdade/não-verdade não pode observar se esta distinção, por seu lado, é verdadeira ou não. Com base na distinção lícito/ilícito não se pode decidir em última instância se a própria distinção é lícita ou ilícita, somente com base em outras distinções anteriores que podem então indicar quais caminhos são válidos para que a distinção presente seja ela mesma lícita ou não; mas a aplicação desta distinção não será válida para a primeira distinção (na primeira vez que ela aparece, o que, no caso do direito, não é mais possível de ser captado), pois ela ainda não tem a qualidade atribuída pela distinção (já que está sendo introduzida). Ela simplesmente ocorre.

Não se pode, então, observar a própria observação no momento que a observação é aplicada e não há distinção que marque ao mesmo tempo dois lados de uma distinção que se aplica: a distinção introduz os dois lados, mas não implica em uma possibilidade de os dois lados serem empregados ao mesmo tempo. A unidade (indivisível) é a própria distinção. Para ver o que um observador não pode ver, precisa-se de um observador de segunda ordem. Tem de se especificar um objeto, a partir do qual se vê o mundo ou em relação ao qual se quer ter uma ideia de como ele ou ela (ou algo neutro = es) "vê" o mundo (LUHMANN, 2008a, p. 156). Isso, por sua vez, ocorre mediante uma distinção que ele (o observador de segunda ordem) não pode observar, só um observador de terceira ordem, e assim por diante. 
No momento da tematização da comunicação, do encontro seletivo com o lado escolhido (o certo ou o errado, o lícito ou o ilícito, etc.) que se torna importante em momentos contextuais do direito, haverá uma tendência para um lado. Abro espaço aqui para uma explicação necessária sobre exemplos que tenho dado com comunicações entre sistemas psíquicos na esfera do direito - além do que já foi explicado na introdução, nas considerações sobre metodologia. Vou parafrasear Luhmann: a comunicação do direito deve se referir, conscientemente, ao direito. Quem (ele usa wer, que significa "quem") se orienta pelo direito já deve saber qual sentido que tem presente. Ele deve referir-se a um sistema jurídico já constituído ou a sedimentos textuais desse sistema (LUHMANN, 1995, p. 48). Assim, as comunicações orientadas desse modo são extensões do sistema jurídico. “Uma comunicação pertence ao sistema jurídico se está coordenada por lícito/ilícito, que é o domínio do código do direito" (LUHMANN, 1995, p. 60-61). Somente o que é apreendido pelo esquema de controle lícito/ilícito pertence ao sistema jurídico. Isso quer dizer que não basta dizer uma palavra como "direito". A questão do direito (lícito/ilícito) tem de ser colocada (LUHMANN, 1995, p. 60-69). Decisões de questões jurídicas se realizam, é verdade, apenas em associação com a função política de tomada de decisões coletivamente vinculantes que garante o recurso ao poder de execução. Mas há uma enorme quantidade de comunicações jurídicas fora da esfera dos parlamentos e tribunais e outras que são criadas sem que se acione essas instâncias, sem qualquer controle político, como mediante contratos (LUHMANN, 1995, p. 74).

Compreendido isso, continuando o que foi colocado no início do parágrafo anterior, o que levará os observadores a escolherem seu lado da distinção nos diferentes contextos que levarão ao contexto final de decisão sobre um fato? E: há algo que legitime isso? Não falo aqui somente de fato julgado, mas de qualquer momento em que se evoca o direito para se decidir sobre algo que necessita de uma avaliação em termos de lícito/ilícito: a polícia que decide levar ou não alguém para a delegacia, que decide abordar ou não alguém, um professor que decide evocar ou não determinado artigo do regimento interno para assim punir um aluno, etc. Como saber de qual lado é a distinção que opera os lados lícito e ilícito? E se não se sabe, como se legitima (pelo procedimento ou processo, poderse-ia argumentar aqui, com base em Luhmann [1983])? A seleção de um dos dois lados não 
é uma questão de justiça, pois ela pode ser feita sem que para vários observadores a classificação (que é uma distinção) de justiça seja aceita. É uma observação aceita operacionalmente como válida para o "sistema jurídico" em um determinado contexto. É uma seleção que teve suas condições para ocorrer desse modo e não daquele. Não se pode dizer que, em última análise, a justiça ou direito fundamentou a decisão do crime $X$ como crime. E quem fundamenta o que está no código no qual a decisão se baseou? Uma decisão anterior. E o fundamento dessa decisão anterior? É justa, é lícita? A regra que em última instância determina o lícito foi determinada licitamente? Seria essa a questão a ser discutida? Não quero aqui acrescentar mais questões a serem ainda refletidas neste texto. Essas convergem para as três questões iniciais deste artigo.

Para se entender melhor isto que pode parecer um excesso de relatividade em relação à perspectiva da distinção de que se fala neste artigo, convém especificar melhor a observação de segunda ordem em relação ao direito. Desse ponto de vista, o direito é um observador que observa observações. E é observado por outros observadores, os quais o distinguem de outra coisa qualquer. Em algum momento a forma do direito passa a existir - o que equivale dizer também que em momento anterior o direito não existia, conforme argumenta Luhmann (2012, p. 24). E então sua distinção se repete (assumindo a forma lícito/ilícito), se impõe pelas comunicações e pelo sentido que elas demandam em determinados contextos. A autopoiese do direito se estabelece e ele então se fundamenta no processo. Isso possibilita um reconhecimento contínuo recursivo da forma do direito (lícito/ilícito), a qual se aplica no cotidiano. Mas essa distinção em si não é a condição primordial do surgimento do próprio direito (LUHMANN, 2012, p. 24). Não há uma razão primordial que se transforma em uso linguístico a posteriori ${ }^{10}$. A validade se impõe por uma questão temporal (o ter de ocorrer aqui e agora) e recorre a uma estrutura que se estabeleceu por comunicações, por repetição e atualização de horizontes de sentido, para se tornar evidente, ser aceita e fazer diferença em diferentes contextos. Assim, as regras do direito, para perdurarem, não podem ser muito fixas. A pretensão de validade universal perante os contextos diferentes geraria paradoxos que as tornaria insuportáveis. Pois uma

\footnotetext{
${ }^{10}$ Como Habermas (1985, p. 374-375) explica em termos de validade e contexto.
} 
regra com uma validade universal seria uma última instância de aplicação de regras: aquela que valeria para as outras. Isso seria a aplicação do código lícito/ilícito sobre si mesmo, aquele paradoxo do direito colocado por Luhmann (1995, p. 72) que mencionei no início deste artigo. De modo que só há validade quando aceita (= assim observada como válida em distinção ao que não é válido) por observadores em determinados contextos. O outro lado do "determinados contextos" é a indeterminação.

Um exemplo de efeito dessa indeterminação. A punição de uma pessoa que não cometeu um crime pode ser aceita pelo direito, desde que em algum ponto no tempo do processo se conclua que a pessoa (que não cometeu o crime) tenha cometido o crime. Mesmo inocente, o direito, no caso, a julga como culpada. Talvez ele proceda assim (enquanto processo) por ignorância, incapacidade, falta de vontade, interesses econômicos, ou políticos, etc. O julgamento em termos de "ter direito a" /"não ter direito a" ou lícito/ilícito prossegue. As atividades de advogados, vítima, réu, agentes, serão também julgadas em termos de lícito e ilícito. Mas, em alguma instância (de legitimação), o direito que está julgando (distinguindo o que lícito e o que é ilícito) não mais será alcançado por essa própria distinção que ele aplica. O direito adianta no tempo uma deliberação e alivia expectativas atuais para que a sociedade possa ocorrer ${ }^{11}$, para que se possa, por exemplo, comunicar sobre um fato passado, com perspectiva de resolução futura (a prova da culpa ou inocência que não se realiza no presente).

Há elementos que não podem ser racionalizados mediante termos que as próprias teorias do direito usam como análise - assim como o sociólogo se vê diante do problema de o objeto de seu conhecimento (o mundo social) ser o mesmo do qual ele é produto e, assim, do qual seus conceitos de análise são produtos ${ }^{12}$. É necessário considerar o que pode ocorrer e ser relevante quando o direito não "vê" (blinder Fleck) e, por outro lado, analisar ou sugerir parte da característica de estados e contextos em que ele, quando "vê", aplica a distinção lícito/ilícito. O que não se vê ou não se cataloga, ou não se registra e é relevante para as ações de várias esferas na sociedade, inclusive o direito, pode ser o que provoca um estímulo, um desejo, uma ideia ou estratégias que serão a base necessária

\footnotetext{
${ }^{11}$ Cf. Luhmann (1987b, p. 94-105 [especialmente p. 100]).

${ }^{12}$ Cf. Bourdieu (2011, p. 33).
} 
para que se leve adiante a ideia de um direito, de aplicação de decisões que orientam expectativas em sociedade. Trata-se de ocorrências em espaços não demarcados por observadores em determinados contextos, mas existentes num espaço não marcado de indeterminação. Explicarei.

O espaço não marcado (unmarked space $^{13}$ ) é o que não pode ser designado pelo sistema, ou, mais especificamente, pelo lado interno do sistema. Ou: pode ser designado pelo lado interno do sistema apenas como um conteúdo vazio (LUHMANN, 1999, p. 609). Como já explicamos, o distinguir produz formas, a qual separa duas áreas, dois lados. Exemplo: o direito é um sistema parcial da sociedade baseado na forma de distinção que recorre sempre a seleções entre duas áreas, dois lados, os lados lícito e ilícito, ou o ter direito e o não ter direito. Essas formas, ao serem evocadas recursivamente, produzem semânticas, que serão usadas para conferir sentido às comunicações dos sistemas. A semântica é então essa forma que fixa o sentido o qual é assim utilizado repetidamente, em forma de palavras, conceitos, afirmações que carregam a pretensão de verdade (LUHMANN, 1995, p. 127). Ou: as semânticas são armazéns temáticos que resultam de condensações de sentido após repetições e esquecimentos (LUHMANN, 1999, p. 1142). No contexto conectivo de condensação da forma, ambos os lados produzem o sentido. Exemplo: o lícito é diferente do ilícito, mas cada lado determina o sentido ou o tipo de sentido do qual se fala. Algo é considerado sob a condição de que outras coisas não são consideradas. Esse "não ser considerado" é determinante para o "ser considerado" (LUHMANN, 1999, p. 213). De modo que ao se observar, há uma seleção de partes do todo. Mas o resto não desaparece. Ele é apenas o espaço não marcado pela forma correspondente.

\section{JOGO E CAMPO DE DETECÇÃO}

Esta seção desenvolve reflexões sobre dois contextos que, seguindo a argumentação deste artigo, podem influenciar justamente a observação nesse estado

\footnotetext{
${ }^{13}$ Termo que Luhmann retira do conceito de unmarked state, de George Spencer-Brown (1972, p. 5 e 14 [especialmente]).
} 
questionado acima: o contexto do jogo e o da fuga do campo de detecção de normas e desvios.

Quando na minha argumentação me refiro a "jogo", tento trabalhar a conotação que se tem dele na língua portuguesa, que mistura, por exemplo, o game, play e o Spiel, sem o sentido de tocar um instrumento. Abaixo, no desenvolvimento conceitual, algumas diferenciações serão explicadas.

Estar num "estado" de jogo não significa necessariamente que se queira estar neste estado, pois, como se verá abaixo, a perspectiva de jogo é a de que ele está presente e é fundamental em nossas vidas, ainda que normalmente não se reconheça consciente nem socialmente isso, principalmente em decisões importantes, e justamente por ele abrir demais a perspectiva normativa - estando o jogo mais presente como fundamento de atividades culturais. Estar num "estado de jogo" significará aqui, baseado em Runkel (1986), estar num quadro de referências do jogo, o que pode ser muito específico e complexo - mas ainda assim os jogadores sabem que naqueles respectivos momentos estão sob regras diferentes.

No caso deste artigo, nesse estado, ao aplicar aquelas distinções jurídicas, o observador poderá não tanto observar a distinção lícito/ilícito para estar em conformidade com o direito (aqui nessa afirmação "direito" no sentido usado de modo mais geral, no cotidiano), mas talvez para fugir ou escapar de um campo detecção que possa detectar sua atividade como ilícita. E essa fuga seria parte de um "jogo".

Quais são as características desse estado de jogo? Iniciamos com Runkel (1986, p. 37). Ele explica que no quadro de referências do jogo (aqui Spiel) há espaço para uma certa ordem e nessa ordem haveria possibilidades para a desordem e espaços para alternativas que não foram necessariamente planejadas. Essas características permitem um enquadramento sem normas rígidas, mas com regulações que para alguns autores devem sempre ser mais rígidas e para outros mais flexíveis e até mesmo abertas. Esses elementos tensivos emitiriam certa indeterminabilidade e com isso chances para uma transformação da sociedade.

Köpping (1997, p. X-XI) afirma que o jogo (play) conecta o social e o natural. Ele é criativo, mas também facilmente destrutivo. O objeto de pesquisa de Köpping é 
exatamente essa força potencialmente criativa como instrumento para a transformação em outras esferas. Observo aqui que essa transformação pode ser resultado de uma prática que se faça combinando elementos lúdicos para interesses próprios.

Temos pelo menos dois autores que nos forneceram abordagens clássicas sobre o jogo: Johan Huizinga e Roger Caillois. O pioneiro em investigação científica sobre o tema é Huizinga (2014). Ele analisou diferentes fundamentos característicos do jogo (ludens) e o significado de seu papel para o desenvolvimento da sociedade. Como ação livre e superficial, o jogo influenciaria o conjunto da sociedade e atuaria como base para todas as atividades culturais. Jogo é para Huizinga uma categoria autônoma. Quer dizer, não é uma categoria dicotômica, ficando fora de dicotomias como verdade e mentira, bom ou ruim, bem e mal. Para Huizinga os elementos do "jogo" são ordem, movimento/variação, tensão (o jogador se envolve em uma tensão, a qual ele procura acabar), entusiasmo e festividade. $\mathrm{O}$ jogo exige necessariamente ordem. Cada jogo tem suas próprias regras. Quer dizer que leis e normas da vida diária não têm a mesma validade nesse contexto. $\mathrm{E}$ tão logo as regras do jogo são corrompidas, ele é interrompido ou acaba (HUIZINGA, 2014, p. 3-25)

Caillois (1982) sugere que em sua operacionalização o conceito de jogo de Huizinga não foi satisfatoriamente definido. Ele tenta esclarecer melhor suas características. Seguem alguns complementos de Caillois em relação a Huizinga. O jogo (jeux) é uma atividade livre, quer dizer, o jogador não tem de necessariamente jogar. É uma atividade demarcada, ou seja, deve ocorrer no interior de limites espaciais e temporais. 0 jogo deve ser uma atividade incerta. Ele é improdutivo, não deve produzir mercadorias nem riqueza ou outro elemento semelhante. O jogo deve ser uma atividade regulada, submetida a convenções que suspendam normas tradicionais e por um momento introduzam nova legislação, ou uma atividade fictícia, acompanhada por uma consciência específica de uma segunda realidade ou de uma irrealidade livre de referência à vida cotidiana. Além disso, Caillois sugere também que a relação entre segredo (e/ou mistério) e jogo não resulta tão claramente em Huizinga. "O jogo produz o mistério, traz ele para a abertura e o dissipa [...]. Se, no entanto, o mistério, a máscara e a fantasia cumprirem uma função sacramental, 
então se pode estar totalmente certo de que não se trata de jogo, mas de instituição" (CAILLOIS, 1982, p. 10-11).

Essas perspectivas de análise de Huizinga e Caillois indicam que no estado de jogo regras cotidianas ficam suspensas pelo tempo de duração dos jogos. São momentos em que algumas regras norteadoras do comportamento ganham vigência, normalmente regras que não se aplicam no cotidiano tradicional. Uma peculiaridade do sentido de "regra" no contexto de jogo é que contém uma abertura para quebra de regras, desde que em conformidade aproximada com o "espírito do jogo". Isso produz uma ordem que prevê, enseja e conta com desordens. Importante notar que a aceitação do desvio das normas orientadoras e de aspectos de "desordem" é uma dinâmica que se desenvolve na participação do jogo, na qual também espectadores podem influir.

O estado de jogo ou lúdico necessita, então, de regras, ainda que de acordo com as interações dos jogadores, elas possam ser flexíveis, conforme formulam Huizinga e Caillois. O que parece não ficar claro nesses autores é como os quadros de referências, ou bordas, ou limites (os frames) são tratados, como se pode tentar esclarecer ou pelo menos refletir sobre essas constituições. Pois fica claro que não se trata de ausência de referências, mas de produção de referências próprias.

Encontro em Bateson e Köpping duas abordagens que podem auxiliar a tratar dessa questão. Bateson (1981, p. 241-261) resume em sua tese sobre "teoria do jogo e da fantasia" ${ }^{14}$ como uma "apresentação da necessidade de paradoxos da abstração" (BATESON, 1981, p. 261), pois é a capacidade de abstrair que pode resolver problemas de comunicação. O paradoxo presente no jogo não permite a determinação de regras muito rígidas. Para o reconhecimento de que determinadas ações que se passam são jogos ou parte de um jogo, os jogadores devem ter capacidade metacomunicativa. Duas pessoas brincando de brigar ou em um jogo de lutas requer o reconhecimento de jogadores e observadores de que não se trata de luta, mas de um jogo, seja competitivo ou não. A própria tentativa de afirmação de que algo seja um jogo ("Isso é um jogo"), e com isso a tentativa de seu delineamento, carrega um paradoxo, pois como parte do jogo, sendo o

\footnotetext{
${ }^{14}$ Trata-se de manipulação de frames na psiquiatria.
} 
objeto um jogo, pode não se tratar de um "jogo". Köpping $(1997$, p. 21) indica o jogar como o próprio limiar, o que cria a margem ou onde a margem ocorre, trazendo em si os riscos e os perigos do limite, do marginal: a ameaça de caos, a indeterminabilidade, a anormalidade. Isso resulta em um estado de suspensão de todas as coisas. É esse estado que pode afastar a sociedade de uma autorreferência estéril e levar a um renascimento do eu (self) (KÖPPING, 1997, p. 31), objeto de estudo de Köpping. Ou seja, voltando a questão colocada no parágrafo anterior, a referência seria constituída pelas possibilidades resultantes da dinâmica do próprio jogo. Os limites estariam suspensos e não poderiam ser colocados por observadores fora do estado lúdico, apenas vivenciados por seus participantes.

Mas a vivência de limites pode depender também do interesse no jogo. Estar nesse estado do jogo é também resultado de um interesse, o qual conduz ao conhecimento de suas regras, de seu "espírito". Bourdieu (2005, p. 139-144; 2011, p. 177-178) vai argumentar que estar preso ao jogo, illusio, é manter interesse pelo jogo, acreditar que ele vale a pena. Se não se tem consciência das estruturas que estão presentes em determinados jogos (seja social, lúdico, etc.), um problema derivado do jogo poderá parecer ridículo. Para o problema ficar evidente é necessário "um espírito estruturado de acordo com as estruturas do mundo no qual você está jogando" (BOURDIEU, 2005, p. 139). É necessário estar incorporado ao jogo, ter o habitus do sentido do jogo para assim saber agir nos respectivos espaços conforme as regras do jogo. Para as reflexões do presente artigo, sugiro reter dessas reflexões de Bourdieu, principalmente que esse "saber agir conforme as regras do jogo" produz um poder específico de entendimento dos limites de determinadas situações. Pode-se também desenvolver a habilidade e as condições para que se participe de atividades consideradas ilícitas em momentos e espaços em que tais atividades não serão consideradas ilícitas. Desenvolverei essa reflexão abaixo com o conceito de fuga do campo de detecção de normas e desvios.

A observação que distingue entre o lícito e o ilícito e como resultado faz valer essa diferença como legítima em decisões relevantes para a vida das pessoas em sociedade é uma observação que muitas vezes designa um lado (o ilícito) daquela distinção como crime. De um modo mais geral, consideramos que o crime é uma construção social. Mas a 
questão, nesse sentido, é saber como essa "construção" se caracteriza. Pode-se imaginá-la, em dois exemplos, como empreendimento moral que produz regras, as quais quando não são seguidas se configuram como desvio ou crime para alguns em determinado contexto (BECKER, 2008). Ou como uma acumulação social que resulta do amálgama de várias representações sociais como estratificações morais, discursos sobre malandragem e estereótipos da mídia ${ }^{15}$.

Gostaria de elaborar a caracterização dessa "construção" de um modo um pouco diferente em seu fundamento, ainda que não discordante do tipo de perspectiva que os dois exemplos acima representam. Para isso, tomarei como base a ideia de um campo de detecção de normas e desvios, desenvolvida em artigo anterior (COSTA, 2008) e à qual acrescento agora novas reflexões com o auxílio dos conceitos acima apresentados nesta e na seção anterior. Por já haver um desenvolvimento específico sobre o conceito no artigo citado, a explicação a seguir da ideia original será breve.

Dessa perspectiva, a percepção ou registro de alguma atividade como crime seria antes uma questão de ser detectado, ou não, por um campo de detecção de normas e desvios. A questão assim não seria tanto se a pessoa desvia, ou não, de determinadas normas, mas se há condições para suas atividades serem detectadas e assim se iniciar qualquer comunicação sobre algo ser crime ou não. O "campo" é o tempo e o espaço em que uma atividade é detectada e percebida como objeto de avaliação entre o lícito e o ilícito. "Detectar" significa aqui "revelar os recursos simbólicos que ocultam, iludem ou, de alguma forma, perturbam a percepção do comportamento desviante. Ou poderíamos também dizer que a capacidade de fugir do campo de detecção significa dispor de recursos simbólicos para ocultar, iludir ou perturbar a percepção do comportamento desviante" (COSTA, 2008, p. 129).

Assim, voltando à questão da caracterização da "construção" do crime, na perspectiva que proponho o processo que define a percepção do lícito/ilícito é "construído" pelo movimento daquela fuga, ou: a construção ocorre como efeito do movimento de fuga. Nessa perspectiva, é esse movimento que definirá o caminho das escolhas que se apresentam como alternativas possíveis.

\footnotetext{
${ }^{15}$ No caso brasileiro, cf. Misse (1999).
} 
A fuga do campo de detecção envolve também a fuga de se ser detectado como jogador (que em seu jogo troca o lícito pelo ilícito e vice-versa) em contextos em que não se espera uma atuação como jogador. Ou seja, isso se refere à fuga de um jogador em um contexto em que jogar não seria considerado legítimo, principalmente quando se usa uma determinada posição ou condição para se estabelecer previamente as condições em que o lícito e o ilícito serão distinguidos. Entenda-se aqui que as teorias sobre jogo acima colocadas não são, claro, teorias para momentos de jogos com regras estabelecidas (com uma partida de um jogo qualquer) - ainda que elas usem esses jogos como exemplos de estados. São teorias de jogo no sentido de um estado lúdico fundamental para a vida. Mas a questão aqui é que normalmente não reconhecemos conscientemente estados de jogo ou lúdicos, principalmente quando temos a expectativa de que regras sejam seguidas em seleções claras. Assim, não se tem a expectativa de que praticar um ato considerado por lei ilegal vale (oficialmente), mas sabemos, sentimos, que algum nível de ilegalidade (em relação às leis), em diferentes níveis de nossa vida diária, é constantemente praticado e tolerado e não chamamos estas práticas de crimes e delitos. No entanto, essa flexibilização não se estende a todos momentos, muito menos, por exemplo, quando se usa um cargo público para obter vantagens pessoais.

A distinção entre lícito/lícito é o resultado formal de observações que se institucionalizaram e assim produziram uma expectativa generalizada de uma atribuição positiva ao lado do "lícito" e uma atribuição negativa ao lado do "ilícito". Mas o uso dessas atribuições em instituições ocorre muitas vezes em estados de jogo por aqueles que têm interesse no jogo e que podem escapar de serem detectados como jogador.

A noção de "ilícito" envolve observações e trocas (que se guiam e se validam de acordo como são observadas) que não se limitam àquilo que se considera como "mundo jurídico", ou "direito" ou "caso de polícia", etc. Essa noção resulta de observações e trocas em várias esferas, como também a econômica e a política. A transação "ilícita" é observada como tal nos contextos em que os observadores observam fora do modo de transação que eles e outros observadores distinguem como moral e/ou juridicamente lícito. São trocas como: dinheiro por droga, favor por dinheiro, favor por favor, permissão para pousar um avião (carregado de drogas) em um certo aeroporto por dinheiro, etc. 
Saber o "quando" e o "onde" e poder estar no tempo e espaço em que as trocas ilícitas serão ignoradas como "ilícitas" ou mesmo consideradas "lícitas" é um objetivo estratégico que considero como fuga do campo de detecção. A questão, então, é efetuar as trocas e não ser detectado.

Assim, sob essa perspectiva de análise a distinção entre o lícito e o ilícito se torna em muitos contextos um efeito de atividades e estratégias de fuga. Essa estratégia é efetiva, pois funciona com e faz uso da crença moral coletiva de que essa distinção existe com base em suas respectivas atribuições positiva e negativa. Ela mantém a crença nessa distinção, pois essas transações ilícitas só valem a pena porque há o outro lado, o (assim observado como) lícito.

\section{ANÁLISE E CONSIDERAÇÕES FINAIS}

Sugiro como resposta geral (somente como desfecho das ponderações feitas acima) àqueles três grupos de questões iniciais colocadas no segundo parágrafo deste artigo:

Não existem em si lados e/ou distinções fixas entre lícito e ilícito, ou: não existe uma fonte legitimadora dessa distinção (com base na qual se obteria uma orientação que fundamentasse tal existência), como se dela emanasse o lícito ou ilícito, seja na forma de um estado, de uma divindade ou de um direito. Nessa perspectiva da colocação do problema existem fundamentalmente jogadores, que, no contexto do jogo, exploram a ideia que coletivamente se tem de existência desses "lados" e naquele contexto predefinem o que deve ser considerado lícito e ilícito. Mais especificamente, jogadores decidem sobre a aplicação da distinção entre lícito e ilícito. É em contexto de jogo que muitas vezes se decide como e quando regras do direito são aplicadas. Observadores em contexto de jogo afastam possibilidades de deteç̧ão do ilícito pelas regras do direito. Como coloca Luhmann (1995, p. 81-82), quando um alto nível de corrupção se estabelece, antes da distinção entre lícito e ilícito há uma distinção anterior mediatizante dessa codificação binária: há algo como um pré-teste sobre a questão de o direito dever ser aplicado ou não, o qual resulta de atividades de elites oportunistas com capacidade de se impor. 
A ideia de lados (lícito/ilícito) ocorre porque há necessariamente distinções. A questão é que esses lados não indicam nenhum valor moral que possa ser atribuído a algum tipo de unidade que geraria valores legitimados. Na perspectiva desse artigo, eles indicam uma forma que é empregada em contexto de jogo depois de a distinção original ter sido estabilizada em um sistema ou em sistemas. A distinção se mantém, mas seu valor de código, a informação (diferença que faz diferença), é invertido. Dois exemplos que ilustram esse argumento seguem abaixo.

Em um jogo de futebol há, em meio a regras, quebras temporárias de valores morais, por vezes até bem rígidos. Pode-se ofender o juiz (o público, os técnicos e jogadores o ofendem constantemente), pode-se agarrar, abraçar forte e ardorosamente, montar em cima e até passar a mão em partes mais íntimas dos jogadores (no momento após um gol ou para discretamente irritar o adversário, por exemplo), desde que não seja feito explicitamente ou por um tempo demasiadamente longo (todos esses são exemplos de uma quebra de valor moral que em determinado contexto, mesmo ali no jogo, poderia não ser tolerada). As normas para não permitir tais transgressões existem e estão à disposição, latentemente, como potencial para se punir esses atos, por reação ou punição conforme regras estabelecidas pelo futebol. Elas podem ser evocadas no momento ou posteriormente registradas na súmula, caso o juiz ou grupo de juízes da partida assim o decida. E, assim, no caso de corrupção de juízes, esse mesmo contexto em que tal tipo de comportamento é normalmente tolerado durante vários momentos da partida, pode, por exemplo, ser observado como um contexto que exija uma punição e sirva assim para favorecer um determinado time.

Segundo exemplo. Por questões de accountability ${ }^{16}$ e de validade da discricionariedade ${ }^{17}$, as regras existentes podem ser comunicadas e aceitas como válidas, mas descritas em um contexto elaborado por agentes com interesses específicos, como no caso dos homicídios cometidos por policiais justificados como "autos de resistência" (MISSE; GRILLO; NERI, 2015). Em muitos casos, os policiais entram em uma casa ou estabelecimento para eles suspeito em um determinado bairro, executam uma ou mais

\footnotetext{
${ }^{16}$ Sobre o sentido empregado aqui ver Cubas (2010, p. 78, 83-87, 92-95).

${ }^{17}$ Ver Linhares (2005, p. 109-111).
} 
pessoas e todos os participantes assinam na delegacia declarações iguais (alterando-se somente os nomes) do mesmo "fato", alegando que reagiram para se defender - embora, entre outros artifícios, tenham plantado evidências falsas (mediante, por exemplo, "kit bandido") (MISSE; GRILLO; NERI, 2015, p. 56). Essas declarações são registradas, aceitas (em um processo de comunicação em que em vários níveis e fases se aceita o que outro afirma) e se tornam "fatos" (MISSE; GRILLO; NERI, 2015, p. 51). A regra para punição deste conjunto existe. Assim como regras (discutidas, comunicadas e aceitas) que permitem que os agentes não sejam punidos - o que ocorre normalmente, conforme resultados daquela pesquisa (MISSE; GRILLO; NERI, 2015, p. 66-69). Por alguma razão, de interesse ou, por exemplo, por um desses casos ter sido revelado e se tornado um escândalo divulgado em meios de comunicação, as regras para punição podem ser evocadas e consideradas como delito grave e claro. A aplicação ou não de certas regras e, principalmente, a validade ou não dessas aplicações serão disputadas ou/e acordadas em contextos. Por um lado, há o problema de participação nesses contextos. Testemunhas podem ter medo de falar sobre o que viram. Por outro lado, em um contexto no qual participam somente determinados agentes, esses podem criar outros contextos que acabarão considerados como "fato", como é o caso do conjunto de declarações dos policiais envolvidos e os aceites dessas comunicações por parte da polícia e do judiciário.

Essa inversão da distinção inicial se estabiliza e tem o potencial de se tornar códigos de troca que são empregados para se ter permissão para fazer algo, independente do código lícito/ilícito do direito. Elas se estabilizam porque criaram sentido usado recursivamente como redutor de complexidade, que se baseia justamente na inversão (o ilícito se torna lícito no contexto dos observadores). E com essa possibilidade de inversão e/ou pré-estabelecimento da validade de códigos, os códigos do direito passam então a ser usados em contexto de jogo.

O direito e aqueles que falam e agem em nome do "direito" o fazem com base em uma distinção entre o que é permitido ou não pelo direito, entre o que pode ser classificado como justo ou injusto, como lícito ou ilícito. A questão é que este direito ou este agente que assim procede não está necessariamente de um lado da distinção ao fazêlo. Ele apenas aplica uma distinção e para que essa aplicação seja ela mesma considerada 
como um lado (atribuído positiva ou negativamente) daquilo que ela própria distingue, muitos recursos podem e são usados. Mas o lado, em si (como se houvesse uma última instância que definisse o "lado"), não existe, somente a sua distinção.

De modo semelhante, quando um sociólogo afirma haver lados e mundos diferentes entre o que possa ou não ser considerado crime, ou que possa ser ou não praticado como crime (que evidenciaria um lado, ou um mundo com suas próprias peculiaridades, como o "mundo do crime") etc., nada além das próprias afirmações e de outras afirmações (de pares, por exemplos) garante que ele mesmo, por exemplo, pode estar de um lado ou de outro, de acordo com a perspectiva aplicada ao se fazer aquelas distinções. Isso vale para mim também, enquanto cientista social, e o conjunto de regras que são a base de minha avaliação e da avaliação que fazem do que produzo no contexto de produção científica, o que seria uma parte fundamental de um sistema científico. Também aqui não há lados, nem mundos diferentes, somente um recurso analítico, o qual pode ser usado pelo "outro lado". É claro que qualquer conceito aplicado por cientistas sociais será um recurso analítico, como se faz neste artigo. Mas a questão aqui seria que esse intrincamento entre a categoria analítica criada por cientistas e um mundo objetivo que se quer assim com ela analisar provoca uma divisão justamente num estado de coisas que não deveria ser analisado fundamentalmente como dividido.

Se eu fosse resumir em poucas palavras o que foi argumentado acima, a síntese seria: não há lados, somente jogadores.

\section{REFERÊNCIAS}

BARALDI, Claudio; CORSI, Giancarlo; ESPOSITO, Elena. Glossar zu Niklas Luhmanns Theorie sozialer Systeme. Frankfurt a.M.: Suhrkamp, 1987.

BATESON, Gregory. Ökologie des Geistes: Anthropologische, psychologische, biologische und epistemologische Perspektiven. Tradução de Hans G. Holl. Frankfurt a.M.: Suhrkamp, 1981.

BECKER, Howard S. Outsiders: Estudos de sociologia do desvio. Tradução de Maria X. de Borges. Rio de Janeiro: Jorge Zahar, 2008. 
BOURDIEU, Pierre. Razões práticas: Sobre a teoria da ação. Tradução de Mariza Corrêa. 7. ed. Campinas: Papirus, 2005.

BOURDIEU, Pierre. O poder simbólico. Tradução de Fernando Tomaz. Lisboa: Edições 70, 2011.

BROWN, George S. Laws of form. New York: The Julian Press, 1972.

CAILLOIS, Roger. Die Spiele und die Menschen: Maske und Rausch. Tradução de Sigrid von Massenbach. München/Wien: Langen-Müller Verlag, 1982.

COSTA, Antônio L. O campo de detecção de normas e desvios. Dilemas, v. 1, n. 2, p. 15138, 2008.

COSTA, Antônio L. O Rio de Janeiro na CPI do Narcotráfico de 1999/2000. Estudos de Sociologia, v. 2, n. 21, p. 75-112, 2015.

COSTA, Antônio L. Irritation und Allopoiesis im Rechtssystem: Eine systemtheoretische Analyse der polizeilichen Beobachtung in der Stadt Teixeira de Freitas, Brasilien. Saarbrücken: Südwestdeutscher Verlag für Hochschulschriften, 2016.

COSTA, Antônio L. Possibilities of empirical research with Luhmann's systems theory. In: BARROS, Marco A. L. L. de; AMATO, Lucas F.; FONSECA, Gabriel F. da (org.). World Society's Law: rethinking systems theory and socio-legal studies. Porto Alegre: Editora Fi, 2020. p. 143-179.

CUBAS, Viviane O. 'Accountability' e seus diferentes aspectos no controle da atividade policial no Brasil. Dilemas, v. 3, n. 8, p. 75-99, 2010.

FELTRAN, Gabriel S. O "mundo do crime" nas periferias de São Paulo. Interações com a sociabilidade urbana e as políticas públicas. 2008. Projeto de pesquisa (Pós-doutorado) Centro de Estudos da Metrópole (CEM), Centro Brasileiro de Análise e Planejamento (CEBRAP), 2008a.

FELTRAN, Gabriel S. O legítimo em disputa: As fronteiras do 'mundo do crime' nas periferias de São Paulo. Dilemas, v. 1, n. 1, p. 93-125, 2008b.

HABERMAS, Jürgen. Der philosophische Diskurs der Moderne: Zwölf Vorlesungen. Frankfurt: Suhrkamp, 1985.

HUIZINGA, Johan. Homo ludens: 0 jogo como elemento da cultura. Tradução de João Monteiro. 8. ed. São Paulo: Perspectiva, 2014.

JAKOBS, Günther. Tratado de direito penal: Teoria do injusto penal e culpabilidade. Tradução de Gercélia O. Mendes e Geraldo de Carvalho. Belo Horizonte: Del Rey, 2008.

JAKOBS, Günther. A imputação objetiva no direito penal. 4. ed. Tradução de André L. Callegari. São Paulo: Editora Revista dos Tribunais, 2013.

KNEER, Georg; NASSEHI, Armin. Niklas Luhmanns Theorie sozialer Systeme. 4. ed. Paderborn: Wilhelm Fink Verlag, 2000. 
KÖPPING, Klaus-Peter. The Ludic as creative disorder: Framing, deframing and boundary crossing. In: Klaus-Peter Köpping (org.). The games of gods and man: Essays in play and performance. Hamburg: LIT Verlag, 1997.

KRAUSE, Detlef. Luhmann-Lexikon. Eine Einführung in das Gesamtwerk von Niklas Luhmann. 4. ed. Stuttgart: Lucius \& Lucius, 2005.

LINHARES, Cláudio R. S. A ambiguidade do inquérito policial. In: AMORIM, Maria S. de; LIMA, Roberto Kant de; MENDES, Regina L. T. (org.). Ensaios sobre a igualdade jurídica: Acesso à justiça criminal e direitos de cidadania no Brasil. Rio de Janeiro: Lumen e Juris, 2005. p. 107-127.

LUHMANN, Niklas. Soziologische Aufklärung 3. Soziales System, Gesellschaft, Organisation, Opladen: Westdeutscher Verlag, 1981.

LUHMANN, Niklas. Legitimation durch Verfahren. Frankfurt: Suhrkamp, 1983.

LUHMANN, Niklas. Soziale Systeme: Grundriß einer allgemeinen Theorie. Frankfurt a.M.: Suhrkamp, 1987a.

LUHMANN, Niklas. Rechtssoziologie. 3. ed. Opladen: Westdeutscher Verlag, 1987b.

LUHMANN, Niklas. Die Wissenschaft der Gesellschaft. Frankfurt a.M.: Suhrkamp, 1992.

LUHMANN, Niklas. Das Recht der Gesellschaft. Frankfurt a.M.: Suhrkamp, 1995.

LUHMANN, Niklas. Die Gesellschaft der Gesellschaft. 2. ed. Frankfurt a.M.: Suhrkamp, 1999.

LUHMANN, Niklas. Ökologische Kommunikation: Kann die moderne Gesellschaft sich auf ökologische Gefährdungen einstellen? 4. ed. Wiesbaden: VS Verlag, 2004.

LUHMANN, Niklas. Einführung in die Systemtheorie. 4. ed. Heildelberg: Carl-Auer, 2008a.

LUHMANN, Niklas. Soziologische Aufklärung 6. Die Soziologie und der Mensch. 3. ed. Wiesbaden: VS Verlag, 2008b.

LUHMANN, Niklas. Gesellschaftsstruktur und Semantik: Studien zur Wissenssoziologie der modernen Gesellschaft 3. 4. ed. Frankfurt a.M.: Suhrkamp, 2012.

MATURANA, Humberto R. Erkennen: Die Organisation und Verkörperung von Wirklichkeit. Tradução de Wolfgang K. Köck. Braunschweig: Springer Vieweg, 1982.

MISSE, Michel. Malandros, marginais e vagabundos: A acumulação social da violência no Rio de Janeiro. Tese (Doutorado) - luperj, Rio de Janeiro, 1999.

MISSE, Michel; GRILLO, Carolina C.; NERI, Natasha. E. Letalidade policial e indiferença legal: A apuração judiciária dos 'autos de resistência' no Rio de Janeiro (2001-2011). Dilemas, ed. esp., n. 1, p. 43-71, 2015.

NASSEHI, Armin. Niklas Luhmann (Soziale Systeme). In: Dirk Kaesler; Ludgera Vogt. Hauptwerke der Soziologie. Stuttgart: Kröner, 2000.

RAMALHO, José R. Mundo do crime: a ordem pelo avesso. São Paulo: IBCCRIM, 2002.

RUNKEL, Gunter. Soziologie des Spiels. Frankfurt a.M.: Suhrkamp, 1986. 
SAAKE, Irmhild. Erleben/Handeln. In: JAHRAUS. Oliver et al. (org.). Luhmann-Handbuch. Leben-Werk-Wirkung. Stuttgart \& Weimar: J. B. Metzler, 2012. p. 77-79.

STICHWEH, Rudolf. Niklas Luhmann (1927-1998). In: Dirk Kaesler. Klassiker der Soziologie. München: C.H. Beck, 2000.

TELLES, Vera S. Jogos de poder nas dobras do legal e do ilegal: anotações de um percurso de pesquisa. In: AZAÏS, Christian; KESSLER, Gabriel; TELLES, Vera S. (org.). Ilegalismos, cidade e política. Belo Horizonte: Fino Traço/Programa de Pós-Graduação em SociologiaUSP, 2012. p. 27-56. 